Editorial

\title{
In Good Company? Personal Relationships, Network Embeddedness, and Social Inclusion
}

\author{
Miranda J. Lubbers \\ COALESCE Lab, GRAFO Research Group, Department of Social and Cultural Anthropology, Autonomous University \\ of Barcelona, Spain; E-Mail: mirandajessica.lubbers@uab.cat
}

Submitted: 8 November 2019 | Published: 15 December 2021

\begin{abstract}
How do individuals' networks of personal relationships affect their social in- and exclusion? Researchers have shown that micro-level, informal relationships can be highly consequential for social inclusion, but in complex, contradictory ways: Personal networks reflect the degree of relational exclusion and protect against (other forms of) exclusion, but they also erode in conditions of exclusion and reproduce exclusion. While network researchers have widely studied some of these mechanisms, they have yet to embrace others. Therefore, this thematic issue reconsiders the complex relationship between personal networks and social inclusion. It offers a unique vantage point by bringing together researchers who work with different marginalised social groups, typically studied separately: refugees, transnational migrants, indigenous people, older people, people experiencing poverty, LGBT people, and women who have experienced domestic violence. This combination allows us to detect commonalities and differences in network functioning across historically excluded groups. This editorial lays the theoretical groundwork for the thematic issue and discusses the key contributions of the seventeen articles that compose the issue. We call for more attention to relationship expectations, the reciprocity of support flows, and contextual embeddedness, and question universally adopted theoretical binaries such as that of bonding and bridging social capital.
\end{abstract}

\section{Keywords}

bonding and bridging; embeddedness; inequality; informal protection; network erosion; personal networks; relationship expectations; reproduction; social inclusion; social relationships

\section{Issue}

This editorial is part of the issue "In Good Company? Personal Relationships, Network Embeddedness, and Social Inclusion" edited by Miranda J. Lubbers (Autonomous University of Barcelona, Spain).

(C) 2021 by the author; licensee Cogitatio (Lisbon, Portugal). This editorial is licensed under a Creative Commons Attribution 4.0 International License (CC BY).

\section{Introduction}

Processes of social exclusion make the headlines every day, whether it is the progressive banishment of women from public life and the oppression of Shia minorities in Afghanistan (and elsewhere), the racial disparities in access to healthcare or higher education in the US (and elsewhere), or the disproportionally negative effect of the Covid-19 pandemic on the vulnerability of people with low incomes worldwide. The events that reach the news are just the tip of the iceberg, as exclusion is a daily, global reality. Social exclusion originates from accumulated histories of opportunity hoarding by categorical groups (Tilly, 1998) and the subsequent legitimisation and rationalisation of inequalities by dominant groups (e.g., Lamont et al., 2014; Lamont \& Pierson, 2019). These processes make people see inequalities as "as natural as the air around us" (Galtung, 1969, p. 173).

The term "social exclusion" gained prominence in the 1990 s to refer to the unequal power relations that generate inequality, contrasting with distributional terms such as poverty. However, it alludes mainly to macrolevel relations among categories of individuals, such as between documented and undocumented residents, which result in unequal access to markets, services, and spaces (Das et al., 2013). In this editorial, I will argue that it is also critical to understand the role of micro-level, interpersonal relationships in reproducing, mitigating, 
or magnifying exclusion. Personal network analysis is well-suited for such research, as it considers the set of social relationships individuals have across the different social circles in which they participate. However, exactly how personal networks bear on exclusion is still unclear. As I will explain, they can (1) reflect the degree of network exclusion, (2) protect against exclusion, (3) erode in conditions of exclusion, and (4) reproduce exclusion (see Figure 1). While network researchers have richly described some of these mechanisms, they have yet to embrace others.

This thematic issue aims to advance this research area by reconsidering how personal networks affect social in- and exclusion. To do so, we have selected authors who work with different marginalised social groups. While these groups are typically studied separately, more contact between personal network researchers working with different groups can help us see the commonalities and differences in network functioning across groups, giving us a better understanding of the intricate relation between networks and social inclusion. Before introducing the articles that compose this thematic issue, I will provide a theoretical framework to help readers place the contributions in the broader literature.

\section{Theoretical Framework}

Personal networks, i.e., the sets of informal social relationships surrounding individuals (McCarty et al., 2019; Perry et al., 2018), give detailed insight into individuals' participation in society's primary and secondary networks (Fischer, 1982; Wellman, 1979). Network composition, and more specifically its heterogeneity in terms of the social groups to which friends, family, and acquaintances belong, is often seen as an indicator of relational inclusion (see Figure 1, relation 1). The extent to which people can build heterogeneous networks depends greatly on the diversity of the social settings they attend, such as workplaces, neighbourhoods, and voluntary associations (Feld, 1981). However, apart from reflecting relational inclusion, personal networks also give a privileged view on the micro-relational mechanisms affecting social in- or exclusion in other areas.

Traditionally, personal networks have been conceptualised as sources of informal social protection (Bilecen \& Barglowski, 2014; see Figure 1, mechanism 2). The conceptualisation of personal networks as safety nets draws primarily on theories of social support (Berkman \& Glass, 2000; Cohen et al., 2000; Taylor, 2011; van Tilburg, 1994) and social capital (Coleman, 1988; Lin, 1999). Social support theories have argued that people mobilise their networks to obtain different types of support, which affects their health and well-being. For instance, Kahn and Antonucci (1980) described personal networks as "social convoys," changing sets of multidimensional relationships that accompany people throughout their lives. When facing adversity, people draw on these convoystheir family members, friends, and acquaintances-for support, which mitigates the stress adversity produces and protects well-being (Cohen \& Wills, 1985; Kawachi \& Berkman, 2001). Social capital theories have further qualified ties and networks. For instance, Granovetter (1973) distinguished between "strong" (intimate and durable) ties, which provide the most emotional and practical support, and "weak ties," which are less supportive overall but particularly well-suited to provide access to novel information about, for instance, employment vacancies or housing. Putnam (1993) distinguished between "bonding" and "bridging social capital." Bonding capital refers to dense networks of relations with people from the same categorical group, which involve thick trust and substantial support for getting by. Bridging capital refers to the less densely connected relations to people of other categorical groups, which can help a person get ahead. Empirical research has consistently observed that personal networks are mobilised in times of forced and voluntary migration (e.g., Bilecen \& Lubbers, 2021; Wissink \& Mazzucato, 2018), mental and physical health issues (e.g., Perry \& Pescosolido, 2012), poverty (e.g. Lubbers, Small, \& Valenzuela-García, 2020; Stack, 1974), reentry in society after imprisonment (e.g., Volker et al., 2016), and widowhood (e.g., Guiaux et al., 2007), among other events. They provide individuals with companionship, emotional, material, economic, and practical support and information, which help them cope with disadvantages and increase their social mobility.

While network scholars thus generally conceive of personal networks as safety nets, exclusion-triggering life events such as migration or the onset of a poverty episode or mental health issues can also substantially change the structure, composition, and resourcefulness of the support networks that are supposed to protect people from the very vulnerability these events induce (see Figure 1, mechanism 3). These events affect networks by (a) reducing individuals' participation in specific social contexts or (b) violating general relationship norms (Lubbers, Valenzuela-García, et al., 2020). Let me give two examples concerning migration and poverty. First, as migrants move far away from their core relationships, they cannot exchange all the types of resources they previously exchanged with these people, leaving their support networks severed. Thus, migrants need to reconstruct their local networks at a moment of great need for social support (Lubbers et al., 2021). Their access to social settings such as work, neighbourhoods (i.e., stable housing), or schools is essential for rebuilding their networks. Second, poverty episodes alter relationships and, therefore, networks' protective capacity. Job loss and lack of money may lead to discontinued participation in work and costly leisure contexts, and thus, to a loss of relationships. Furthermore, while people experiencing poverty mobilise support from their networks, relationships become conflictive when people cannot meet norms of reciprocity for extended periods (e.g., Hansen, 2004; Komter, 1996), ultimately excluding them from family networks and balanced personal relationships 
(Lubbers, Valenzuela-García, et al., 2020). In sum, the erosive effects of "biographical network disruptions" (Perry \& Pescosolido, 2012) temper the idea of networks being safety nets.

The protective effect of networks is not only hampered by biographical network disruptions, however. While exclusion is historically rooted in macro-level categorical relations and supported by systemic forces, individuals enact and reproduce them in everyday interactions, intentionally and unintentionally (see Figure 1, mechanism 4). We clearly see this in interactions among strangers and professional relationships. For instance, Taliban men physically blocked women and girls from entering workplaces and schools to enforce their rules, and health professionals give differential treatment and pain management to patients of different races with the same health conditions (Lee et al., 2019), as a result of racial bias (Hoffman et al., 2016). However, informal relationships among family members, friends, neighbours, colleagues, classmates, members of the same community of worship, or parents whose children go to the same school also reproduce exclusion. Categorically unequal relationships with power differentials are particularly prone to reproducing exclusion. For instance, informal mixed-race relationships can exert racial micro-aggressions (Williams, 2020), more affluent family, friends, and acquaintances can shame and stigmatise people experiencing poverty (e.g., Garthwaite, 2015), and documented citizens sometimes exploit their undocumented friends or relatives (del Real, 2019). Consequently, marginalised groups tend to distrust others (Levine, 2013) or hide their status (e.g., as benefit recipient; see Garthwaite, 2015) for good reasons, decreasing support mobilisation. Understanding how the two parties of an unequal relationship interpret and negotiate power differentials is, therefore, fundamental, but this topic has been underrepresented in social network analysis (cf. Azarian, 2010).

\section{The Thematic Issue}

The seventeen articles in this thematic issue reconsider the complex role of personal networks in social in- and exclusion processes. Their authors adopt a qualitative or quantitative personal network approach to investigate how marginalised social groups experience exclusion in their networks and how their relationships protect them from or expose them to further vulnerability.

The unique vantage point of this thematic issue is that it brings together social network scholars who study different marginalised social groups, related to migration (Habti, 2021; Hoor, 2021; Hosnedlová et al., 2021; ten Kate et al., 2021), refuge (Brinker, 2021; Korkiamäki \& Elliott O'Dare, 2021; Speed et al., 2021; Younes et al., 2021), indigenous ethnic minorities (Huszti et al., 2021), poverty and economic exclusion (de Miguel-Luken \& García-Faroldi, 2021; Huszti et al., 2021; ValenzuelaGarcia et al., 2021), advanced age (Ferguson, 2021; Korkiamäki \& Elliott O'Dare, 2021; Ortiz \& Bellotti, 2021), socioeconomic status (Hanhörster et al., 2021), sexual orientation (Rengers et al., 2021), and domestic violence (Bellotti et al., 2021)-as well as the general population (Requena \& Ayuso, 2021). These populations are typically studied separately, governed by different research interests. For example, for migrants, network researchers focus on the process of relational embedding (Ryan, 2018) within a new society of residence; for people experiencing poverty, on the extent to which individuals mobilise material support; and for older people, on loneliness. However, bringing these areas together may reveal commonalities and differences in network functioning across dimensions of exclusion, as well as intersectionality (for the latter, cf. Habti, 2021; Huszti et al., 2021; Speed et al., 2021; ten Kate et al., 2021).

The questions we initially asked the authors were: How beneficial are personal networks for social inclusion? Under which conditions do personal relationships and networks contribute to, versus impede, social inclusion? Which interventions reinforce the protective capacities of networks? The transversal themes that emerged across the articles, which I will summarise below, were related to these questions.

\subsection{Relationship Expectations Qualify the Supportiveness of Ties}

Various articles observe that personal network effects on well-being cannot be understood by only focusing on

\section{Meso- and macro-level contexts}

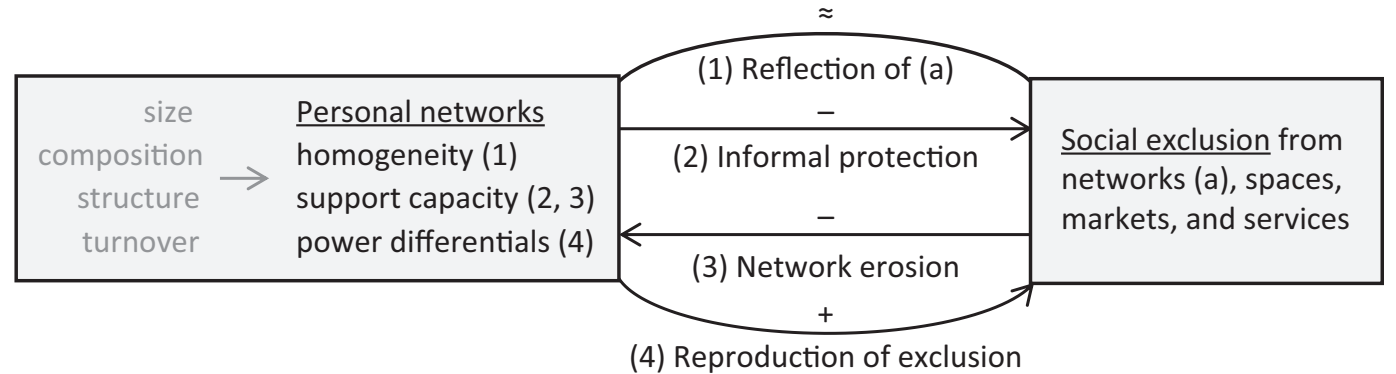

(4) Reproduction of exclusion

Figure 1. Relation between personal networks and social exclusion. 
the amount of social support without considering individuals' relational expectations about support. A relationship is a "force-field" (Azarian, 2010, p. 328) where individuals negotiate contrasting expectations. Focusing on women who experienced domestic violence, Bellotti et al. (2021) formalise this complexity by crossing the supportiveness of ties with women's relational expectations about support. They distinguish between positive and negative "consistency" (i.e., receiving expected support and not receiving non-expected support, respectively) and positive and negative "ambivalence" (i.e., receiving non-requested support and being denied requested support, respectively) in relationships. They use this classification to show that agreement on the framing of the situation and the modalities of help (i.e., consistency) is vital for victims' disclosure and escape.

The lens these authors introduce resonates with other findings presented in this thematic issue. For instance, ten Kate et al. (2021) show that older migrants' unfulfilled expectations about their adult children's support, rather than support itself, are related to loneliness. They, too, use the term "ambivalent relationships." Focusing on older people in care homes, Ferguson shows that adult children give essential support, but they do not always meet parental expectations, and sometimes they restrict their parents' agency, making such relationships "ambiguous." Rengers et al. (2021) demonstrate how LGB individuals carefully consider expected acceptance of colleagues and weigh their own, sometimes conflicting, needs for belonging and authenticity in the decision to disclose their sexual orientation at work. Younes et al. (2021) direct our attention to the expectation of support providers. Dutch citizens who voluntarily helped Syrian refugees in a housing initiative expected refugees' gratefulness and unlimited availability, exacerbating relationship inequality. Brinker (2021) focuses on another grassroots initiative that aims to enhance the inclusion of refugees, namely the international NGO Refugees Welcome, which connects homeowners who have a spare room with refugees in need of housing. Based on previous analyses of power differentials in such arrangements, she analyses the role of the intermediaries the organisation assigns to these arrangements to compensate for potential power imbalances in the refugee-home owner dyad. She finds that intermediaries give refugees a sense of safety and balance, but they can also disconnect when not feeling needed (again indicating relationship expectations) or overprotect refugees. Together, these analyses show the need to consider relationship expectations and negotiations (or "control attempts"; White, 2008) for categorically unequal ties.

These relational dynamics and the aggregation of relations make personal networks extraordinarily complex entities to study. Unsurprisingly, personal networks are infrequently studied over time, let alone over a lifetime. Yet, as Ortiz and Bellotti (2021) show, social in- or exclusion results from an "accumulated history"
(Bourdieu, 1986) of life events and network functioning that cannot always be reduced to current levels of social capital. The authors adopt an innovative retrospective life-history approach to reconstruct network trajectories over time. Studying retirement exclusion, they show that cumulative (dis)advantage describes the trajectories of the majority of respondents, but a minority experienced changes from disadvantageous to advantageous trajectories or vice versa.

\subsection{Questioning Theoretical Binaries and Common Assumptions}

Theoretical binary distinctions such as those of strong and weak ties (Granovetter, 1973) or bonding versus bridging social capital (Putnam, 1993) have often been reduced to platitudes over time, concealing more nuanced realities (Patulny \& Lind Haase Svendsen, 2007). The articles in this issue question these binaries and other sometimes taken-for-granted assumptions about personal networks.

Regarding strong versus weak ties, Younes et al. (2021) show that ties between refugees and volunteers in a neighbourhood initiative could not be classified as weak nor strong, as they had characteristics of both types of ties (e.g., intense contact, but distant lifeworlds). They called such ties "hybrid." Many articles show that strong ties are not always supportive, and weak ties can be unexpectedly highly supportive.

Regarding the conception of bonding versus bridging social capital, both Younes et al. (2021) and Speed et al. (2021) show that intra-ethnic networks should not be equated with the qualities often attributed to "bonding networks," such as thick trust and horizontality. Internal divisions of education, socioeconomic status, ethnicity, religion, or life stage (Speed et al., 2021) and competition over material resources, connections, and information (Younes et al., 2021) divided the networks of Syrian refugees, showing the need for an intersectional lens to reevaluate bonding and bridging social capital.

Similarly, Habti (2021) focuses on highly-skilled Russian migrants in Finland, who combine a high professional status with a migrant background. His respondents had the opportunity to professionally connect with locals in the work context (i.e., "bridging" in one social setting) but had similar difficulty establishing close ties with locals as observed for other migrants with lower professional positions.

Related to bonding, an assumption commonly found in personal network research is that large and dense personal networks are better suited to provide material and emotional support than smaller and sparser networks. However, in a quantitative analysis of the overall population, de Miguel-Luken and García-Faroldi (2021) find that these network characteristics are unrelated to higher economic inclusion. Instead, the average occupational status of non-kin relations is related to inclusion. In a qualitative analysis of women in households 
experiencing poverty, Valenzuela-Garcia et al. (2021) further show that large and dense networks can go hand in hand with loneliness. In this vein, higher network density can reflect bonding, but also a restricted number of social settings (Feld, 1981). In Valenzuela-Garcia et al. (2021), what caused feelings of loneliness among those women were the many care tasks these women had toward their network members, many of whom were in similar conditions of precarity. These findings and those of other authors in this thematic issue also question the idea that refugees (Younes et al., 2021), women who experienced domestic violence (Bellotti et al., 2021), and people experiencing poverty (Valenzuela-Garcia et al., 2021) are predominantly recipients of support, ignoring the help they provide to others and how this affects their well-being.

Regarding academic preconceptions about friendship, Korkiamäki and Elliott O'Dare (2021) argue that intergenerational friendships have received insufficient scholarly attention. Their empirical study observes that such friendships are vital sources of support and belonging and can be an excellent alternative for support from age peers. Furthermore, they found that intergenerational friendships are characterised by equality and reciprocity, challenging the supposed "generational order" of support flows from older to younger individuals.

Regarding the idea that migrants have high migratory capital (i.e., relationships with earlier migrants), Hosnedlová et al. (2021) argue that relationships with non-mobile people are equally necessary for migration. The authors further find that people with a high proportion of kin and friends in countries outside a transnational migration corridor are not highly mobile themselves.

Together, these results suggest that binary distinctions such as weak versus strong ties and bonding versus bridging social capital are critical theoretical devices but should not conceal the complexity of real-life social situations.

\subsection{Macro-Level Contexts Affect Network Functioning}

The articles in this issue also stress that the spatial, institutional (cf. Small, 2009), and structural contexts in which networks are embedded affect network functioning. Interventions may therefore target such contexts to reinforce the protective capacities of networks.

Two articles compared spatial contexts. Hanhörster et al. (2021) compare three neighbourhoods with diverse social classes and ethnicities. While personal network research concerning social inclusion usually focuses on respondents from marginalised social groups, these authors cleverly flip the lens to study middle-class people and their in- and exclusionary practices (e.g., boundarydrawing and "bridging-out" to other neighbourhoods). This perspective on hegemonic groups indicates a relevant avenue for future personal network research in the area of social inclusion. The authors show that even in disadvantaged neighbourhoods, some middle-class fam- ilies explicitly seek diversity and non-exclusionary spaces. They also argue that successful mixing requires a certain level of policy mediation and leading-by-example.

Huszti et al. (2021) show that the spatial segregation of economically excluded communities aggravates relational exclusion. Comparing three marginalised communities with distinct levels of spatial segregation in the same city but comparable population characteristics, they found differences in personal networks' spatial and ethnic homogeneity. Individuals in the spatially most integrated community had, perhaps somewhat surprisingly, most bonding ties on average, and in addition, Roma inhabitants of this area had spatially and ethnically more diverse bridging capital than Roma inhabitants elsewhere.

While not explicitly studying them, the participating authors acknowledge the effects of organisational contexts on network composition and mobilisation. Ferguson (2021) focuses on older residents of seven care homes and finds that their policy of person-centred care fails to the extent that residents do not nominate staff as support providers. Adult children were primary support providers, and external friendships were pivotal to maintaining connections to wider communities and church groups. No resident made new friends in care homes, which identifies an unfulfilled opportunity. Rengers et al. (2021) studied LGB individuals' disclosure of their sexual orientation at work in an explicitly LGBT-friendly organisation, and encouraged similar research in less inclusive organisational climates for comparison. Younes et al. (2021) evaluated a grassroots organisation for accommodating refugees, which provided a safety net for these people in highly vulnerable conditions. Nonetheless, they show that the good intentions of leaders and volunteers do not guarantee social inclusion, as unacknowledged power differentials between refugees and locals resulted in prejudice and privacy invasions.

Social settings that have received relatively little attention in personal network research that focuses on social inclusion are online networks. Focusing on the general population, Requena and Ayuso (2021) show that participation in online networks complements offline networks in generating subjective well-being. Interestingly, personality influences the extent to which people resort to online networks and benefit from them. The results can inspire social inclusion researchers to study whether online networks mitigate or magnify the inclusion of different marginalised communities.

For structural contexts, two articles compare groups of individuals with different rights in the same structural context. Speed et al. (2021) observe that the broader legislative context recognises different migration and asylum routes, creating distinct individual opportunity structures, which affect relational embedding processes. Similarly, Hoor (2021) delineates the personal networks of migrants with two legal statuses (asylum-seekers versus expatriates) in the same structural context and shows that the two groups vary in personal network size, the 
number of transnational ties, and access to friendship and support.

Together, these analyses remind us that the mesoand macro-level contexts in which networks are embedded can greatly constrain or promote meeting opportunities and network functioning. Empirical comparisons of network functioning across different contexts, or across populations with different rights in the same context, are needed to improve our comprehension of the relationship between personal networks and social inclusion.

\section{Conclusion}

This introduction described the state of the art of research into the relationship between personal networks and social inclusion and presented the seventeen articles included in the issue. By bringing together studies about different social groups, the thematic issue reveals interesting commonalities, such as the impact of relational expectations on in-/exclusion, the need to consider the care and social support that marginalised people provide to others, alternative sources of support such as online networks and intergenerational friendships, and the constraining or promoting effects of spatial, organisational, and structural contexts. The authors have further shown that common theoretical distinctions and assumptions can conceal relationship differences that are consequential for inclusion.

In light of the findings regarding relationship expectations and assessments, personal network analysts may find it helpful to seek a closer alignment with relational sociology. Qualitative network researchers already build upon and contribute to relational sociology, but it is also valuable for network-structural analyses. Future research could investigate whether and how relationship expectations are structurally embedded, detect the different roles that network members play in terms of in- and exclusion, or analyse the relational benefits that exclusion implies for the excluders (cf. Wyer \& Schenke, 2016). We hope that this thematic issue inspires readers to take up such research.

\section{Acknowledgments}

I am most grateful to the authors for their original contributions to this thematic issue and their dedicated work, to the anonymous reviewers for their valuable feedback on the articles, and to Mariana Pires and the editorial team of Social Inclusion for their fantastic help editing this thematic issue. I would also like to thank the La Caixa Foundation (grant no. SR0587) and ICREA Acadèmia for their financial support.

\section{Conflict of Interests}

The author declares no conflict of interests.

\section{References}

Azarian, R. (2010). Social ties: Elements of a substantive conceptualization. Acta Sociologica, 53(4), 323-338.

Bellotti, E., Boethius, S., Åkerström, M., \& Hydén, M. (2021). Ambivalent and consistent relationships: The role of personal networks in cases of domestic violence. Social Inclusion, 9(4), 211-221.

Berkman, L. F., \& Glass, T. (2000). Social integration, social networks, social support, and health. In L. F. Berkman \& I. Kawachi (Eds.), Social epidemiology (pp. 137-173). Oxford University Press.

Bilecen, B., \& Barglowski, K. (2014). On the assemblages of informal and formal transnational social protection. Population, Space and Place, 21(3), 203-214.

Bilecen, B., \& Lubbers, M. J. (2021). The networked character of migration and transnationalism. Global Networks, 21(4), 837-852.

Bourdieu, P. (1986). The forms of capital. In J. Richardson (Ed.), Theory and research in the sociology of education (pp. 241-258). Greenwood Press.

Brinker, L.-D. (2021). Security net and ambassadors for social inclusion? The role of intermediaries in hostrefugee relationships in homestay programs. Social Inclusion, 9(4), 232-242.

Cohen, S., \& Wills, T. A. (1985). Stress, social support and the buffering hypothesis. Psychological Bulletin, 98(2), 310-357.

Cohen, S., Underwood, L. G., \& Gottlieb, B. H. (Eds.). (2000). Social support measurement and intervention. A guide for health and social scientists. Oxford University Press.

Coleman, J. S. (1988). Social capital in the creation of human capital. American Journal of Sociology, 94, 95-120.

Das, M. B., Fisiy, C. F., \& Kyte, R. (2013). Inclusion matters: The foundation for shared prosperity. New frontiers of social policy. World Bank Group. http:// documents.worldbank.org/curated/en/114561468 $154469371 /$ Inclusion-matters-the-foundation-forshared-prosperity

de Miguel-Luken, V., \& García-Faroldi, L. (2021). Two sides of the coin: The link between relational exclusion and socioeconomic exclusion. Social Inclusion, 9(4), 339-349.

del Real, D. (2019). Toxic ties: The reproduction of legal violence within mixed-status intimate partners, relatives, and friends. International Migration Review, 53(2), 548-570.

Feld, S. (1981). The focused organization of social ties. American Journal of Sociology, 86(5), 1015-1035.

Ferguson, J. M. (2021). How do the support networks of older people influence their experiences of social isolation in care homes? Social Inclusion, 9(4), 315-326.

Fischer, C. S. (1982). To dwell among friends: Personal networks in town and city. University of Chicago Press. 
Galtung, J. (1969). Violence, peace, and peace research. Journal of Peace Research, 6(3), 167-191.

Garthwaite, K. (2015). "Keeping meself to meself": How social networks can influence narratives of stigma and identity for long-term sickness benefits recipients. Social Policy \& Administration, 49(2), 199-212.

Granovetter, M. (1973). The strength of weak ties. American Journal of Sociology, 78(6), 1360-1380.

Guiaux, M., van Tilburg, T., \& van Groenou, M. B. (2007). Changes in contact and support exchange in personal networks after widowhood. Personal Relationships, 14, 457-473.

Habti, D. (2021). Differentiated embedding and social relationships among Russian migrant physicians in Finland: A narrative socio-analysis. Social Inclusion, 9(4), 266-277.

Hanhörster, H., Ramos Lobato, I., \& Weck, S. (2021). People, place, and politics: Local factors shaping middle-class practices in mixed-class German neighbourhoods. Social Inclusion, 9(4), 363-374.

Hansen, K. V. (2004). The asking rules of reciprocity in networks of care for children. Qualitative Sociology, 27(4), 421-437.

Hoffman, K. M., Trawalter, S., Axt, J. R., \& Oliver, M. N. (2016). Racial bias in pain assessment and treatment recommendations, and false beliefs about biological differences between blacks and whites. Proceedings of the National Academy of Sciences of the United States of America, 113(16), 4296-4301.

Hoor, D. (2021). A privilege not a choice: Transnational support networks of asylum seekers and expatriates. Social Inclusion, 9(4), 254-265.

Hosnedlová, R., Fradejas-García, I., Lubbers, M. J., \& Molina, J. L. (2021). Structural embeddedness in transnational social fields: Personal networks, international (im)mobilities, and the migratory capital paradox. Social Inclusion, 9(4), 278-290.

Huszti, É., Albert, F., Csizmady, A., Nagy, I., \& Dávid, B. (2021). When spatial dimension matters: Comparing personal network characteristics in different segregated areas. Social Inclusion, 9(4), 375-387.

Kahn, R. L., \& Antonucci, T. C. (1980). Convoys over the life course: Attachment, roles, and social support. In P. B. Baltes \& O. Brim (Eds.), Life-span development and behavior (pp. 253-286). Academic Press.

Kawachi, I., \& Berkman, L. F. (2001). Social ties and mental health. Journal of Urban Health, 78(3), 458-467.

Komter, A. E. (1996). Reciprocity as a principle of exclusion: Gift giving in the Netherlands. Sociology, 30(2), 299-316.

Korkiamäki, R., \& Elliott O’Dare, C. (2021). Intergenerational friendship as a conduit for social inclusion? Insights from the "book-ends." Social Inclusion, 9(4), 304-314.

Lamont, M., Beljean, S., \& Clair, M. (2014). What is missing? Cultural processes and causal pathways to inequality. Socio-Economic Review, 12(3), 573-608.

Lamont, M., \& Pierson, P. (2019). Inequality generation and persistence as multidimensional processes: An interdisciplinary agenda. Daedalus, 148(3), 5-18.

Lee, P., Le Saux, M., Siegel, L., Goyal, M., Chen, C., Ma, Y., \& Meltzer, A. C. (2019). Racial and ethnic disparities in the management of acute pain in US emergency departments: Meta-analysis and systematic review. American Journal of Emergency Medicine, 37(9), 1770-1777.

Levine, J. (2013). "Ain't no trust": How bosses, boyfriends, and bureaucrats fail low-income mothers and why it matters. University of California Press.

Lin, N. (1999). Social networks and status attainment. Annual Review of Sociology, 25, 467-487.

Lubbers, M. J., Molina, J. L., \& McCarty, C. (2021). How do migrants' processes of social embedding unfold over time? Global Networks, 21(3), 529-550.

Lubbers, M. J., Small, M. J., \& Valenzuela-García, H. (2020). Do networks help people to manage poverty? Perspectives from the field. Annals of the American Academy of Political and Social Science, 689(1), 7-25.

Lubbers, M. J., Valenzuela-García, H., Escribano Castaño, P., Molina, J. L., Casellas, A., \& Grau Rebollo, J. (2020). Relationships stretched thin: Social support mobilization in poverty. Annals of the American Academy of Political and Social Science, 689(1), 65-88.

McCarty, C., Lubbers, M. J., Vacca, R., \& Molina, J. L. (2019). Conducting personal network research: $A$ practical guide. Guilford Press.

Ortiz, F., \& Bellotti, E. (2021). The impact of life trajectories on retirement: Socioeconomic differences in social support networks. Social Inclusion, 9(4), 327-338.

Patulny, R., \& Lind Haase Svendsen, G. (2007). Exploring the social capital grid: Bonding, bridging, qualitative, quantitative. International Journal of Sociology and Social Policy, 27, 32-51.

Perry, B. L., \& Pescosolido, B. A. (2012). Social network dynamics and biographical disruption: The case of 'first-timers' with mental illness. American Journal of Sociology, 118(1), 134-175.

Perry, B. L., Pescosolido, B. A., \& Borgatti, S. P. (2018). Egocentric network analysis: Foundations, methods, and models. Cambridge University Press.

Putnam, R. D. (1993). Making democracy work: Civic traditions in modern Italy. Princeton University Press.

Rengers, J. M., Heyse, L., Wittek, R. P. M., \& Otten, S. (2021). Interpersonal antecedents to selective disclosure of lesbian and gay identities at work. Social Inclusion, 9(4), 388-398.

Requena, F., \& Ayuso, L. (2021). Online networks and subjective well-being: The effect of "big five personality traits." Social Inclusion, 9(4), 399-412.

Ryan, L. (2018). Differentiated embedding: Polish migrants in London negotiating belonging over time. Journal of Ethnic and Migration Studies, 44(2), 233-251.

Small, M. L. (2009). Unanticipated gains: Origins of net- 
work inequality in everyday life. Oxford University Press.

Speed, F., Scurry, T., Edward, P., \& Moufahim, M. (2021). Networks amongst Syrians: Situated migrant positionalities and the impact on relational embedding. Social Inclusion, 9(4), 243-253.

Stack, C. B. (1974). All our kin: Strategies for survival in a black community. Harper \& Row.

Taylor, S. E. (2011). Social support: A review. In M. S. Friedman (Ed.), The handbook of health psychology (pp. 189-214). Oxford University Press.

ten Kate, R. L. F., Bilecen, B., \& Steverink, N. (2021). The role of parent-child relationships and filial expectations in loneliness among older Turkish migrants. Social Inclusion, 9(4), 291-303.

Tilly, C. (1998). Durable inequality. University of California Press.

Valenzuela-Garcia, H., Lubbers, M. J., \& Molina, J. L. (2021). "She's surrounded by loved ones, but feeling alone": A relational approach to loneliness. Social Inclusion, 9(4), 350-362.

van Tilburg, T. G. (1994). Social network size and support. In D. J. H. Deeg \& M. Westendorp-de Serière (Eds.), Autonomy and well-being in the aging population I: Report from the longitudinal aging study Amsterdam (pp. 79-88). VU University Press.

Volker, B., De Cuyper, R., Mollenhorst, G., Dirkzwager, A., van der Laan, P., \& Nieuwbeerta, P. (2016). Changes in the social networks of prisoners: A comparison of their networks before and after imprisonment. Social Networks, 47, 47-58.

Wellman, B. (1979). The community question: The intimate networks of East Yorkers. American Journal of Sociology, 84(5), 1201-1231.

White, H. (2008). Identity and control: How social formations emerge. Princeton University Press.

Williams, M. T. (2020). Microaggressions: Clarification, evidence, and impact. Perspectives on Psychological Science, 15(1), 3-26.

Wissink, M., \& Mazzucato, V. (2018). In transit: Changing social networks of Sub-Saharan African migrants in Turkey and Greece. Social Networks, 53, 30-41.

Wyer, N. A., \& Schenke, K. C. (2016). Just you and I: The role of social exclusion in the formation of interpersonal relationships. Journal of Experimental Social Psychology, 65, 20-25.

Younes, Y., Ghorashi, H., \& Ponzoni, E. (2021). Conflicting experiences with welcoming encounters: Narratives of newly arrived refugees in the Netherlands. Social Inclusion, 9(4), 222-231.

\section{About the Author}

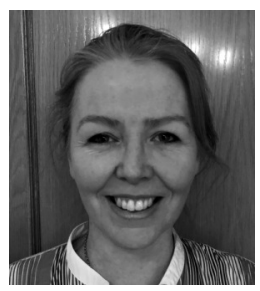

Miranda J. Lubbers is an associate professor of anthropology at the Autonomous University of Barcelona and director of the COALESCE Lab. She is an ICREA Acadèmia fellow and an ERC advanced grant-holder. Her recent work has appeared in Social Networks, Global Networks, Annals of the American Academy of Political and Social Science, Human Nature, and International Migration Review. She is one of the co-authors of the book Conducting Personal Network Research: A Practical Guide (Guilford Press, 2019). 